\title{
Research on the social identity of adolescents with deviant behavior
}

\author{
Oksana Isaakian ${ }^{1, *}$ and Marina Lukyanenko ${ }^{1}$ \\ ${ }^{1}$ Kuban State University, Slavyansk-on-Kuban, 350040, Russia
}

\begin{abstract}
Introduction. The difficultly predictable socio-economic and socio-moral difficulties of modern society at the stage in the development of our society have exacerbated the problem of upbringing and formation of adolescents, which negatively affects the process of their adaptation and socialization. This issue is addressed at different levels: legal, medical, psychological, social. Theoretical justification In adolescence, identity goes through a phase of formation, being in the zone of proximal mental development. Identity and identification are important characteristics of selfawareness. Timely identification of identification disorders makes it possible to detect deviations in the formation of identity in adolescents, which is extremely important both for diagnosing the personality of adolescents with deviant behavior and for their correction. Results. The problem of the formation of the social identity of adolescents with deviant behavior puts before the authors of the article the need to search for directed and indirect technologies for working with adolescents, taking into account the characteristics of their personality. The authors proved the difference in the social identity of adolescents with normalized behavior and adolescents with deviant behavior and identified the features of the social identity of adolescents with deviant behavior, having received a qualitative assessment after using diagnostic methods and analysis of the data obtained. The discussion of the results. The analysis of psychological and pedagogical technologies for the formation of the social identity of adolescents with deviant behavior has shown the possibility of using patterns of successful, socially approved behavior for various aspects of adolescent life.
\end{abstract}

\section{Introduction}

The study of personality traits of adolescents with deviant behavior is relevant for modern society in psychological, pedagogical and social terms. Difficulties in learning, labor social adaptation of adolescents with behavioral disorders poses a number of difficult tasks for special psychology: research, diagnostic, corrective and preventive. Therefore, the psychological and pedagogical community is trying to answer a number of questions that have arisen in modern society: how are elements of personal and impersonal behavior, different in nature and essence, integrated in one and the same person; how the choice of behavior is carried out, how is the shift from normative to deviant behavior, is there a gap

\footnotetext{
*Corresponding author: otana20@yandex.ru
} 
and contradiction in their levels, how is the integrity of the personality formed and what factors influence this process [1].

To get answers to these and many other questions, one can turn to the theory of social identity. The search for people close in spirit, ideas, significant groups, role models is very important throughout a person's life, but it becomes especially significant for adolescents.

The effective solution of the listed tasks at the present stage will increase the level of psychological and pedagogical work with future generations and, accordingly, the moral purity and stability of society. To prevent the occurrence of deviations, early recognition of personality changes leading to deviations in behavior is necessary.

\subsection{Purpose of this article}

The purpose of this article is to analyze identification disorders and deviations in the formation of identity in adolescents and to identify the possibility of using patterns of successful, socially approved behavior for various aspects of adolescent life.

\subsection{Presentation of the main material}

Social identity is a phenomenon that arises on the basis of a person's awareness of his belonging to various social groups, into which a person is included in the course of his life, the result of the process of social identification. Social identification performs important functions, both at the group and personal level: it is thanks to this process that society gets the opportunity to include individuals in the system of social connections and relationships, and the individual realizes the basic need of group belonging, providing protection, opportunities for self-realization, evaluation by others and influence on group [2, 3].

The study of the characteristics of social identity, as well as its formation in adolescence, acquires special significance due to the fact that it is at this age that an intensive process of their formation takes place, which largely determines the characteristics of the personality and behavior of a teenager [4].

It is known that adolescents with a normal course of mental development have certain age-related problems caused by physical, psychological and social factors. In adolescents with deviant behavior, these problems are more pronounced [5]. Thus, adolescence is an important preparatory stage for the further development of identity. In recent years, the problem of the formation of a person's social identity has been increasingly studied in foreign and domestic psychology. Interest in this problem is associated with the growing processes of migration, mobility in the world community, the expansion of business and intercultural interaction and the development of new types of communication. In the conditions of a rapidly changing society, the established ideas of a person about himself and his place in the social world are constantly being tested and ultimately become issues of social identity. G. M. Andreeva, N. M. Lebedeva, V. S. Mukhina, T. G. Stefanenko define that social identity is one of the factors that make up the psychological basis of a person's conscious behavior in various social conditions, which once again emphasizes the importance of addressing this problem $[6,7,8,9]$.

Studies of the phenomenon of social identity were carried out by representatives of various directions: psychoanalysis (E. Waterman, E. Erickson) [10], symbolic interactionism (D. Mead, S. Strucker) [11, 12, 13], behaviorism (D. Campbell, M. Sheriff) [14], cognitive and constructionist approaches (A. Tashfel, J. Turner) [9]. However, this concept was first introduced in the works of E. Erickson in 1968, where identity is considered as the most important characteristic of the integrity of the individual, identifying oneself with certain social groups of a given society [10]. 
In Russian psychology, the phenomenon of identity appeared only in the mid-nineties of the last century in the works of N.V. Antonova, N. M. Lebedeva, V. N. Pavlenko, G. U. Soldatova and T. G. Stefanenko. According to the definition of domestic authors, social identity is the result of a person's awareness of his or her group belonging and the adoption of norms and rules corresponding to this group $[9,15]$.

First of all, the formation of social identity is facilitated by the social environment of the adolescent [16].

The social situation as a condition of development and being in adolescence is fundamentally different from the social situation in childhood, not so much for external circumstances as for internal reasons. The teenager continues to live in a family, to study at school, he is surrounded for the most part by the same peers. However, the social situation itself is transformed in his consciousness into completely new value orientations, the teenager begins to intensely reflect on himself, on others, on society, otherwise accents are placed. Family, school, peers acquire new meanings and meanings [17].

In adolescence, it is time to assess loved ones. Previously, the child was immersed in the field of family identification. Family "We" is the first group that is taken for granted in childhood. The parents themselves, relatives, their world of things, family traditions, the style of relationships in childhood are perceived as the unchanging essence of being. However, acquiring life experience, the teenager discovers a variety of family relationships that differ from the parental family. At the same time, he begins to feel the need to part with family identification, feeling the need for a more universal, broader identity and at the same time to strengthen his own sense of personality, to separate his "Self" from the family "We" [18, 19].

Upbringing, family environment influence the formation of a teenager's identity. If the relationship with the parents is bad, then most often there is an implicit diffuse identity, excessive attachment, symbioticity lead to an immature identity. Democratic relations in the family contribute to a greater adaptability of the adolescent to the world around him [20].

Of course, the social situation of a teenager's life largely determines the formation of his social identity and personality in general. But it itself does not contain those specific conditions, specific people and circumstances that each time with all certainty would have only a beneficial or only negative influence on a teenager.

So, the formation and development of social identity in adolescence is promoted, first of all, by the social environment of the adolescent and, first of all, by his peers. In communication with peers, he expands the boundaries of his knowledge, develops mentally, sharing his knowledge and demonstrating the mastered ways of mental activity. Communicating with peers, a teenager comprehends different forms of human-human interactions, learns to reflect on the possible results of his own and someone else's actions, statements, emotional manifestations. The teenager takes an active position in relation to the community in which he realizes himself as a person and which becomes for him a mirror reflecting his personal qualities, primarily in relation to close-knit groups [21].

Thus, the problem of studying the formation of social identity in adolescence consists in the need to comprehend the process of self-determination, the formation of value orientations in adolescence, taking into account the fact that the process of socialization is taking place today in conditions of uncertain social situations, a variety of principles of organizing social communities, types of activities, social roles and group norms, which ultimately affects the process of forming the identity of the younger generation. The study of the problems of the formation of social identity is also of practical importance for the development of recommendations aimed at organizing the successful educational process of adolescent children. 


\section{Materials and Methods}

To achieve the goal of the study, which was to analyze identification disorders and deviations in the formation of identity in adolescents and to identify the possibility of using patterns of successful, socially approved behavior for various aspects of adolescent life, we carried out a study at the MBOU secondary school in Slavyansk-on-Kuban. The study involved 93 adolescents aged 13 to 15 years. Of these: 42 girls and 51 boys.

Research methods: methodology for diagnosing deviant behavior of minors (TDB-test tendency to deviant behavior), developed by a team of authors (E. V. Leus, ASTU named after M. V. Lomonosov; A. G. Soloviev, SSMU, Arkhangelsk); T. Leary's method of diagnostics of interpersonal relations; methodology "Determination of the formation of value orientations" B. S. Kruglov (adapted and modified version of the methodology of M. Rokich) and test "Who am I?" M. Kuhn [22].

\section{Results}

In the course of analyzing the results of diagnosing deviant behavior of minors (TDB-test tendency to deviant behavior), it was found that out of 93 adolescents there are 24 (26\% of the studied) children with a high degree of socio-psychological maladjustment, of which only 16 children are registered (54,2\% of children with deviant behavior). Nine adolescents ( $10 \%$ of the subjects) showed a mild degree of socio-psychological maladjustment. Out of 24 children, a high level of socially conditioned behavior was found in 8 adolescents (33\%), indicators of the severity of dependent behavior were found in 4 adolescents $(17 \%)$, selfinjurious behavior was found in 5 adolescents $(21 \%)$, aggressive behavior - in 5 adolescents ( $21 \%)$, delinquent behavior - in 2 adolescents $(8 \%)$. The rest of the adolescents have no signs of socio-psychological maladjustment $-64 \%$ of the respondents. Considering the results obtained, we can conclude that no girl has aggressive or delinquent behavior, the indicators of conditioned, dependent, self-injurious behavior were the same. Moreover, the number of girls in this group does not exceed boys by any type.

Among boys, conditioned ( 5 adolescents) and aggressive ( 5 adolescents) behavior is most common, followed by self-injurious and delinquent behavior ( 2 adolescents).

The data show that there is a group of adolescents who need close attention and psychological and pedagogical support from the school teacher-psychologist, class teacher and parents. A graphic representation of the results obtained by us is presented in Figure 3, in which we can see that we have 8 people with pronounced socially determined behavior, 4 people with pronounced addictive behavior, 5 people with pronounced aggressive behavior, 2 people with pronounced delinquent behavior and 5 a person with pronounced self-injurious behavior.

The analysis of the results obtained by T. Leary's method of diagnosing interpersonal relations in the studied group of respondents showed that the selfish type of interpersonal relations is typical for 13 adolescents (14\%). Such adolescents strive to be above everyone, but at the same time aloof from everyone. Of these, 10 people have a mild level of sociopsychological maladjustment (ML TDB-test) or its absence. Three have a high level of sociopsychological maladjustment (HL TDB-test). They are characterized by narcissism, prudence, boastfulness, arrogance. The difficulties that arise are mostly passed on to others.

In 10 adolescents, which is $11 \%$, an aggressive type of interpersonal relationship was revealed, which is characterized by straightforwardness, intransigence, irritability, and a tendency to blame others for everything. Of these, 2 people show either an absence or a mild level of socio-psychological maladjustment, and 8 people with a high level of sociopsychological maladjustment. 
7 teenagers $(8 \%)$ are authoritarian in relations with others. Of these, 5 people show either an absence or a mild level of socio-psychological maladjustment, and 2 people with a high level of socio-psychological maladjustment. They are energetic, self-confident, persistent and persistent, love to give advice, demand respect for themselves. Everyone is instructed, instructed, seeks to rely on his own opinion in everything, does not know how to accept the advice of others.

Also, among the subjects, 15 adolescents revealed a dependent type of interpersonal relationship (16\%), in which they do not show their character, their behavior often depends on the behavior of others. Of these, 11 people show either an absence or a mild level of sociopsychological maladjustment, and 4 people with a high level of socio-psychological maladjustment.

Suspiciousness, characterized by the desire to keep away from peers, was revealed in 4 adolescents (4\%). Of these, 2 people show either no or a mild level of socio-psychological maladjustment and 2 people with a high level of socio-psychological maladjustment. They show alienation in relation to a hostile and evil world, suspicious, touchy, prone to doubt everything, vindictive, constantly complaining about everyone, unhappy with everyone (schizoid type of character).

The subordinate type of behavior is characteristic of 13 adolescents in this group (14\%). Of these, 9 people show either no or a mild level of socio-psychological maladjustment, and 4 people with a high level of socio-psychological maladjustment. They are passive, submissive, prone to self-humiliation, give in to everyone and in everything, always put themselves in last place, and condemn themselves, ascribe to themselves guilt, strive to find support in someone stronger.

A friendly type of behavior prevails in 22 adolescents, which is $23 \%$. Of these, all 22 people show either an absence or a mild level of socio-psychological maladjustment. These teens are friendly and cooperative. When communicating, they can be flexible, when solving problems or in conflict situations, they tend to compromise. Consciously conform, in relations with people they follow conventions, rules and principles of "good taste". They strive to help, feel in the center of attention, earn recognition and love, are sociable, show warmth and friendliness in relationships. However, the manifestations of this type of interaction were not extreme, the average values ranged from 7 to 8 , which means that the adolescents were not friendly and kind to absolutely everyone, their behavior was not focused solely on acceptance and social approval, they do not seek to satisfy the requirements of everyone, "Being good" for everyone, regardless of the situation. And there is not a single person who would show friendliness and was with a high level of socio-psychological maladjustment.

9 adolescents (10\%) showed an altruistic type, but none of these values crossed the norm, which suggests that these adolescents are delicate, kind, responsible towards people, disinterested and responsive, they show an emotional attitude towards people in caring, compassion, sympathy, they know how to cheer up and calm others. At the same time, not a single teenager turns such behavior into negative manifestations - hyperresponsibility, sacrificing oneself and one's interests. On this scale, there is also not a single person who would show altruism and had a high level of socio-psychological maladjustment.

Analyzing the results of the methodology, we found that adolescents with both a mild level of socio-psychological maladjustment and a high level of socio-psychological maladjustment are characterized by such characteristics of interpersonal relations as: selfishness, aggression, authoritarianism, dependence, suspicion and obedience. At the same time, selfishness and authoritarianism are more characteristic of adolescents with a mild level of socio-psychological maladjustment. Suspicion, obedience is inherent in them equally. But not a single child with a high level of revealed socio-psychological maladjustment has a pronounced friendly or altruistic type of attitude. 
Children with normalized behavior, absence and mild level of socio-psychological maladjustment showed some adherence to the egoistic, dependent and submissive type, but on average, they had higher values for the friendly and altruistic type, they were less inclined to the aggressive type. This indicates that these adolescents have working patterns of positive social interaction. But only 31 teenagers observed positive values on the entire scale, that is, only they have a pronounced tendency to form a positive social identity, since they have developed positive models of interaction with society.

Such results indicate that adolescents with socio-psychological maladjustment have a tendency to build relationships that negatively affect the formation of social identity. This means that the rest of the adolescents need to carry out preventive work aimed not only at eliminating manifestations of social and psychological maladjustment, helping them to develop scenarios for successful positive interaction, but also building a clear positive social identity.

Analysis of the results of the study of terminal values according to the modified method of studying value orientations by $\mathrm{M}$. Rokich showed that adolescents attach the greatest importance to such values as pleasure (11\%), public recognition $(11 \%)$, materially secured life $(11 \%)$, active active life $(10 \%)$.

Наличие хороших друзей (8\%), счастливая семейная жизнь (8 \%), свобода (7 \%), уверенность в себе $(6 \%)$, здоровье (6\%) считаются важными ценностями, но число подростков, считающих так, сравнительно невелико.

Having good friends (8\%), a happy family life $(8 \%)$, freedom $(7 \%)$, self-confidence $(6 \%)$, health $(6 \%)$ are considered important values, but the number of adolescents who think so is relatively small.

Insignificant values were recognized: beauty (2\%), life wisdom (1\%), cognition ( $1 \%)$, development $(1 \%)$, happiness of others $(1 \%)$. These values were put in last place by many teenagers.

Such results indicate that students do not consider these values as guidelines for their immediate development.

An analysis of the research results on instrumental values showed that the most significant are values such as honesty $(11 \%)$, cheerfulness $(9 \%)$, courage in defending one's opinion, views $(8 \%)$, strong will ( $8 \%)$.

A smaller number of elections received independence $(8 \%)$, responsibility $(8 \%)$, education ( $7 \%$ ), high demands ( $7 \%$ ), good manners $(7 \%)$, but these values were also among the priorities.

The following are of low significance: intolerance of the shortcomings of oneself and others $(1 \%)$ and efficiency in business $(1 \%)$, open-mindedness $(2 \%)$, tolerance $(3 \%)$, sensitivity $(3 \%)$.

Based on the results of this methodology, it can be concluded that the position of adolescents in relation to socially significant values is unstable, therefore there are a lot of adolescents in the class who do not attach primary importance to these values, which indicates a weak formation of social identity.

Thanks to the latest methodology, the test of M. Kuhn and T. McPartland "Who am I", we revealed the peculiarities of adolescents' perception of their self-image. The scale of this technique includes 24 indicators, which, when combined, form seven generalized indicatorscomponents of identity. The complexity of the analysis of the results of this study was that this technique is used in the form of free associations, which means that more time is needed to process and analyze the obtained values.

Analyzing the descriptions of adolescents, we identified the following patterns in their descriptions.

The situational state manifested itself in the description of only $10 \%$ of children; in all cases, the description was associated with the emotional state. 
The problematic identity affected only 2 teenagers. They wrote that it is difficult for them to determine who they are. These children also previously showed a tendency to socially conditioned behavior on TDB-test and the submissive type according to Leary's method.

"Social Self" all adolescents described themselves most fully with gender, educational, professional, role and family identity, such an identity is well developed in all children (indicated by $100 \%$ of adolescents). Teenagers quite often wrote "boy" \"girl", "schoolboy" \ "schoolgirl", "student" \"student", "son" \"daughter", "grandson" \ "granddaughter". It was more difficult for adolescents to define ethnic and regional identity (3 adolescents indicated), ideological identity (10 adolescents indicated), group affiliation (5 adolescents indicated). Not a single teenager indicated a sex role.

It is worth noting that adolescents with revealed socio-psychological maladjustment almost did not notice or poorly noted, or noted with negative connotations "Communicative Self". Also, "Perspective Self" was hardly spelled out. In the "Reference Self", many noted a quick irritability, a tendency to disobey their elders. The "active self" often described that adolescents do not like to do their homework, they like to have fun. Self-destructive teens wrote that they enjoy hurting themselves. Teens with aggressive behaviors wrote that they enjoy hurting others (one of the descriptions remarked that "especially those with whom I am not friends"). Often they used negative descriptions about themselves or others, emphasizing that they were "different", that their adults did not understand, that they could not find contact with adults and parents.

Thus, on the basis of our research, we identified the features of the social identity of adolescents with deviant behavior and received a qualitative assessment based on the use of three methods and analyzed the data obtained.

From the data analyzed, it becomes clear that children with normative behavior have patterns of successful, socially approved behavior that help them develop a positive social identity. In adolescents who do not have such models, social identity is formed much worse or it is negatively colored.

\section{Discussion}

Based on the results of the research work, we can talk about its effectiveness and formulate the following conclusions.

1. Our study proved the difference in the social identity of adolescents with normalized behavior (with mild or no socio-psychological maladjustment) and adolescents with deviant behavior (with a high degree of socio-psychological maladjustment).

2. Children with normative behavior have patterns of successful, socially approved behavior that help them develop a positive social identity. In adolescents who do not have such models, social identity is formed much worse or it is negatively colored.

3. Preventive work on leveling deviant behavior and developing patterns of successful, socially approved behavior that helps adolescents to develop a positive social identity should be based on the formation of a reflexive adolescent position to create a field for his selfrealization as a personality and individuality. This activity will help fulfill the frustrated needs that are accumulating in adolescents and provide a release of the energy of unreacted negative emotions.

The results presented in the article may be of interest for further study of the problem of prevention of deviant behavior and the formation of patterns of successful, socially approved behavior that helps adolescents to develop a positive social identity. 


\section{Conclusion}

Preventive and developmental impact on the leveling of deviant behavior and the formation of patterns of successful, socially approved behavior that helps adolescents to develop a positive social identity can be implemented in educational institutions with the maximum coverage of school specialists: psychologist, teachers, social worker, head teacher for educational work and other employees organizations. Early detection of signs of deviant behavior in a teenager will allow timely corrective work.

\section{References}

1. P.S. Samygin, Prevention of deviant behavior of youth (Yurajt Publ., Moscow, 2019)

2. M.P. Barbolin, Socialization of personality: methodology, theory, practice (Petropolis, St. Petersburg, 2008)

3. A.V. Miklyaeva, Social identity of a person: content, structure, mechanisms offormation (Herzen University Publ., St. Petersburg, 2008)

4. E.D. Bozhovich, Journal of Psychological Science and Education 2, 5-13 (2007)

5. E.V. Zmanovskaya, Deviantology (psychology of deviant behavior) (Akademiya Publ., Moscow, 2008)

6. G.M. Andreeva, Social Psychology (Aspekt Press Publ., Moscow, 2007)

7. G.M. Andreeva, Psychology of social cognition (Aspekt Press Publ., Moscow, 2009)

8. B.C. Mukhina, Age-related psychology (Akademiya Publ., Moscow, 2000)

9. T.G. Stefanenko, Social psychology of ethnic identity. Doctoral dissertation (MSU, Moscow, 1999)

10. E. Erickson, Childhood and society (Piter Publ., St. Petersburg, 2019)

11. G. Mead, Culture and the world of childhood (Direkt-Media Publ., Moscow, 2007)

12. G. Mead, Internalized Others and the Self (Self and Society, Chicago, 1934)

13. S. Stryker, Identity theory: Developments and extensions (Self and Identity, NY, 1986)

14. A.A. Rean, Psychology of deviance: Children. Society. Law (Yuniti-Dana Publ., Moscow, 2016)

15. N.M. Lebedeva, Introduction to Ethnic and Cross-Cultural Psychology (Klyuch-S Publ., Moscow, 1998)

16. Yu.V. Obukhova, Modern practical psychology in providing resources for personal selfrealization (Southern Federal University Publ., Rostov-on-Don, 2016)

17. I.V. Abakumova, M.V. Godunov, A.L. Enin, Z.Sh. Generdukaeva, Meaning-making strategies: modern concepts in the works of Russian researchers (CREDO Publ., Moscow, 2016)

18. I.V. Abakumova, Meaning formation in the educational process. Doctoral dissertation (RSU, Rostov-on-Don, 2003)

19. M.I. Shilova, Socialization and education of the personality of schoolchildren in the pedagogical process (FLINTA Publ., Moscow, 2014)

20. Yu.A. Kleyberg, Psychology of deviant behavior (Yurajt Publ., Moscow, 2017)

21. M.N. Filippov, Segments of the social and pedagogical sphere (State Social and Humanitarian University Publ., Moscow, 2015)

22. I.V. Vasilieva, Psychodiagnostics (FLINTA Publ., Moscow, 2013) 